\title{
Ohmic Heating—a Novel Approach for Gluten-Free Bread Baking
}

\author{
Denisse Bender ${ }^{1,2}$ (D) Maximilian Gratz ${ }^{1}$ (D) $\cdot$ Silvan Vogt ${ }^{3} \cdot$ Thomas Fauster $^{1,2}$ (D) Beata Wicki $^{3} \cdot$ Stefanie Pichler $^{1} \cdot$ \\ Mathias Kinner $^{3} \cdot$ Henry Jäger ${ }^{1}$ (D) $\cdot$ Regine Schoenlechner $^{1}$ (i)
}

Received: 7 January 2019 / Accepted: 12 August 2019 / Published online: 21 August 2019

(C) The Author(s) 2019

\begin{abstract}
Gluten-free (GF) batters usually present several technological challenges that limit the performance during conventional baking and the resulting product quality. Due to the volumetric heating principle and faster heating rates, ohmic heating $(\mathrm{OH})$ may be advantageous compared with conventional baking. Therefore, the potential of using ohmic heating as a novel approach for gluten-free bread baking was explored. In detail, the effect of different $\mathrm{OH}$ process parameters (power input, holding time) on the chemical and functional properties (specific volume, crumb firmness and relative elasticity, pore properties, color, starch gelatinization) and digestibility of breads was investigated. Results showed that GF breads could benefit from the uniform rapid heating during processing, as these breads showed superior functional properties (specific volume, $2.86-3.44 \mathrm{~cm}^{3} / \mathrm{g}$; relative elasticity, 45.05-56.83\%; porosity, 35.17-40.92\%) compared with conventional oven-baked GF bread (specific volume, 2.60 $\mathrm{cm}^{3} / \mathrm{g}$; relative elasticity, $44.23 \%$; porosity, $37.63 \%$ ). In order to maximize bread expansion and the $\mathrm{OH}$ performance, it was found that the $\mathrm{OH}$ process could be improved by applying the electrical energy in three descending power steps: first step with high power input (in this study, 2-6 kW for $15 \mathrm{~s}$ ), followed by $1 \mathrm{~kW}$ for $10 \mathrm{~s}$, and $0.3 \mathrm{~kW}$ for 1-30 min. In total, ohmic baking only needed a few minutes to obtain a fully expanded GF bread. The determination of pasting properties and starch digestibility demonstrated that these breads were comparable or even superior to GF breads baked in a conventional baking oven.
\end{abstract}

Keywords Ohmic heating $\cdot$ Baking $\cdot$ Gluten-free $\cdot$ Digestibility $\cdot$ Starch gelatinization

\section{Introduction}

In conventional baking, wheat bread is usually produced from doughs with a water content of about 55-60\%. After various fermentation periods (around $2 \mathrm{~h}$ for pure yeast fermentation, up to several days for sourdough fermentation), the dough is baked in baking ovens (contact heat or convection oven) for approximately $1 \mathrm{~h}$, whereby heat is transferred from the outside to the inside of the dough until it reaches its maximum core temperature of around $100{ }^{\circ} \mathrm{C}$ and is then held for drying and
Regine Schoenlechner

regine.schoenlechner@boku.ac.at

Denisse Bender

denisse.bender@boku.ac.at

Maximilian Gratz

maximilian.gratz@boku.ac.at

Silvan Vogt

vogtsil1@students.zhaw.ch

Thomas Fauster

thomas.fauster@boku.ac.at

Beata Wicki

beata.wicki@hotmail.com
Stefanie Pichler

s.pichler1@gmx.net

Mathias Kinner

mathias.kinner@zhaw.ch

Henry Jäger

henry.jaeger@boku.ac.at

1 Department of Food Science and Technology, BOKU-University of Natural Resources and Life Sciences Vienna, Muthgasse 18, 1190 Vienna, Austria

2 FFoQSI GmbH - Austrian Competence Centre for Feed and Food Quality, Safety and Innovation, Technopark 1C, 3430 Tulln, Austria

3 Life Sciences and Facility Management, Zürich University of Applied Sciences, Einsiedlerstrasse, 29,

8820 Wädenswil, Switzerland 
crust formation (Mondal and Datta 2008). In contrast, GF bread formulations usually require twice as much water than for wheat bread. Since the protein network is missing, the gas retention is mainly controlled by the starch gelatinization during baking and hence a higher water addition is needed (Schoenlechner et al. 2010). However, this results in a lower dough viscosity and together with the different gas retention of the starch matrix compared with a gluten network in wheat bread, baking of GF bread is challenging when applying conventional technologies.

$\mathrm{OH}$ is an emerging technology that has shown many advantages over other heating methods. Heat is distributed in a very rapid and uniform manner, as heating occurs volumetrically and does not rely on conventional heat transfer based on conduction, convection or radiation (Sakr and Liu 2014; Varghese et al. 2014; Jaeger et al. 2016). Main parameters affecting the heat generation during $\mathrm{OH}$ are the electrical field strength and the electrical conductivity of the material. Both determine the electrical current and result in a temperature increase based on the total specific energy input applied and the specific heat capacity of the material (Icier 2012). The applied power affects the heating rate. In a heterogeneous material such as food, the electrical conductivity closely depends on certain properties (e.g., composition, $\mathrm{pH}$, concentration, and mobility of ions) and usually increases with temperature, water, and salt content (Kumar et al. 2014).

No more than a few investigations have focused on applying $\mathrm{OH}$ for the production of crustless bread (using a water addition of 55-60\%), and positive effects regarding bread quality and shelf life over conventional baking have been recognized (Derde et al. 2014; Gally et al. 2016; Hayman et al. 1998). Other studies have only used $\mathrm{OH}$ as a tool for modeling the baking process, rather than as a baking technology itself (Chhanwal et al. 2012; Masure et al. 2018). As for GF bread making, there is only one study reported in literature so far that has focused on baking with $\mathrm{OH}$ (Masure et al. 2018). In that study, $\mathrm{OH}$ heating temperature profiles were adjusted in order to simulate conventional baking and $\mathrm{OH}$ was only used as a tool for studying crumb formation.

Based on the process characteristics of $\mathrm{OH}$ which provides high heating rates and short heating times together with a volumetric heat generation, it is expected that baking time can be reduced. Also, it is expected that gas retention can be further reinforced due to a better structure fixation at an early baking stage, resulting from the rapid heating. This is of particular interest for GF breads considering the challenge that batter properties represent in conventional baking, but might be well suited for $\mathrm{OH}$ due to the high water content and an appropriate electrical conductivity. The overall aim of this work was to investigate the potential of $\mathrm{OH}$ to produce GF breads and to identify quality parameters that could benefit from ohmic baking compared with conventional baking. Therefore, the impact of $\mathrm{OH}$ process variables such as power input and holding time on the functional bread properties as well as on crumb pasting behavior and starch digestibility of $\mathrm{OH}$ breads was investigated.

\section{Material and methods}

\section{Materials}

Buckwheat grains were obtained from Caj. Strobl Naturmühle $\mathrm{GmbH}$ (Linz-Ebelsberg, Austria) and ground at $12000 \mathrm{rpm}$ in a pin mill (Fa. Pallmann Maschinenfabrik, PXL 18, Zweibrücken, Germany) for wholemeal flour production. For baking, compressed baker's yeast (Hagold Hefe GmbH, Vienna, Austria), salt (Salinen Austria, Ebensee, Austria), and sugar (Agrana Vienna, Austria) were purchased from the local market. Gluten-free wheat starch was bought from Kröner Stärke (Ibbenbüren, Germany), while hydroxypropyl methylcellulose (HPMC; Metolose®, Shin Etsu Chemical Col, Ltd, Tokyo, Japan) was donated from HARKE Services GmbH (Muelheim an der Ruhr, Germany). Egg albumen and vegetable fat powder (REVEL®) were purchased from EnthovenBouwhuis Eiprodukten B.V. (Raalte, Netherlands) and Loders Croklaan B.V. (Wormerveer, Netherlands), respectively. The emulsifier was a mixture of 3 parts diacetyl tartaric acid ester of monoglyceride (Panodan-DATEM A2020, DuPont Nutrition and Health, Grindsted, Denmark) and 5 parts distilled monoglyceride (Dimodan PH 100, NS/B, DuPont Nutrition and Health, Grindsted, Denmark). All used reagents were of analytical grade and purchased from Sigma-Aldrich Co. (Steinheim, Germany).

\section{Gluten-free bread production}

Preparation of batter Based on Phimolsiripol et al. (2012), GF bread formulation and baking conditions were previously optimized and adapted as follows: For preparing the batter, dry ingredients (100 g buckwheat flour, $100 \mathrm{~g} \mathrm{GF}$ wheat starch, $4 \mathrm{~g}$ egg albumen, $6 \mathrm{~g}$ HPMC, $4 \mathrm{~g}$ vegetable fat, $3 \mathrm{~g}$ salt, $2 \mathrm{~g}$ emulsifier) were homogenized with a laboratory dough mixer (Bär Varimixer RN10 VL-2, Wodschow \& Co., Brondby, Denmark) for $1 \mathrm{~min}$. Then, $6 \mathrm{~g}$ baker's yeast and $3 \mathrm{~g}$ sugar were dissolved in $220 \mathrm{ml}$ water and poured into the dry mixture. Mixing process continued for $4 \mathrm{~min}$ at step 2. The resulting batter was rested in a fermentation chamber (Model 60/rW, MANZ Backtechnik GmbH, Creglingen, Germany) at $30{ }^{\circ} \mathrm{C}$ and $85 \%$ R.H. (relative humidity) for $10 \mathrm{~min}$. Afterwards, two batter portions of $400 \mathrm{~g}$ in case of conventional baking or one $350 \mathrm{~g}$ portion for $\mathrm{OH}$ breads were accurately weighed into a baking tin or ohmic heating cell and subsequently fermented at $30{ }^{\circ} \mathrm{C}$ and $85 \%$ R.H. for $40 \mathrm{~min}$. Due to the large bread expansion during ohmic baking, the batter portion of the $\mathrm{OH}$ breads had to be reduced to $350 \mathrm{~g}$.

Conventional baking Control breads were baked in a deck oven (Model 60/rW, MANZ Backtechnik GmbH, Creglingen, Germany) at $180{ }^{\circ} \mathrm{C}$ for $60 \mathrm{~min}$. Dimensions of baking tins $(\mathrm{L} \times \mathrm{W} \times \mathrm{H})$ consisted of $15 \times 11 \times 7 \mathrm{~cm}$ (bottom 
dimension of tin) to $13 \times 9 \times 7 \mathrm{~cm}$ (top dimension of tin). After baking, the breads were cooled down and stored at $20^{\circ} \mathrm{C}$ and $50 \%$ R.H. for $18 \mathrm{~h}$ before being analyzed. Baking trials were performed in triplicate, resulting in a total amount of six breads.

Ohmic heating-experimental design Ohmic heating of breads was performed in a pilot scale $\mathrm{OH}$ unit from the German Institute of Food Technologies (DIL, Quakenbrück, Germany). The power supply generates rectangular bipolar direct-current pulses at a frequency of $12 \mathrm{kHz}$ and a maximum voltage of $1000 \mathrm{~V}$. The pulse width of the generated pulses is adjusted by the generator in the range of 10 to $40 \mu$ s in order to control the power.

The ohmic heating treatment chamber used for the experiment was designed to resemble the baking tin used in conventional baking and possessed following dimensions: $15 \times 9 \times$ $7 \mathrm{~cm}(\mathrm{~L} \times \mathrm{W} \times \mathrm{H})$. Electrodes were made of stainless steel with a thickness of $3 \mathrm{~mm}$ and were $15 \mathrm{~cm}$ apart. Core temperature of the bread batter was monitored by a PT-100 stainless steel thermometer (FuehlerSysteme eNET International $\mathrm{GmbH}$, Nürnberg, Germany). Figure 1 shows the treatment chamber with batter and temperature sensor.

Breads were baked at different heating profiles, which resulted by varying power $(0.5-7.5 \mathrm{~kW})$ and holding times $(0.25-10 \mathrm{~min})$. During pre-trials, suitable breads were qualitatively evaluated based on two main criteria: the bread should be completely baked (no doughy surfaces) and should not burn during heating. After several pre-trials, it was observed that a three step heating profile with a stepwise reduction of the power level was found to be most suitable. This reduced the risk of crumb burning, but ensured that the bread was fully baked at all surfaces. Once a suitable heating profile was found, the power level of each step was individually varied in order to determine its effect on the bread properties. Power levels in the range of 2 to $8 \mathrm{~kW}$ were applied in step 1 for $15 \mathrm{~s}$ (corresponding to an electric field strength of 33 to $67 \mathrm{~V} / \mathrm{cm}$ ), followed by the application of $1 \mathrm{~kW}$ for $10 \mathrm{~s}$ and $0.3 \mathrm{~kW}$ for a final holding time of $0-30 \mathrm{~min}$. After $\mathrm{OH}$, breads were cooled and stored at $20^{\circ} \mathrm{C}$ and $50 \%$ R.H. for $18 \mathrm{~h}$ before analysis. All baking trials were performed at least in duplicate.

\section{Bread quality determination}

To determine the specific volume of each bread, the rapeseeds replacement method of the AACC approved Method 55-50.01 (2000) was used. Specific volume $\left(\mathrm{cm}^{3} / \mathrm{g}\right)$ was calculated as the ratio of the volume $\left(\mathrm{cm}^{3}\right)$ and the mass of the bread $(\mathrm{g})$. Duplicate measurements were performed for each bread, obtaining 4 values for each tested condition.

A compression test to estimate crumb firmness and relative elasticity of breads was performed following the AACC standard Method 74-09.01 (2000) with some modifications. A Texture Analyzer (Model TA-XT2i, Stable Microsystems ${ }^{\text {TM }}$
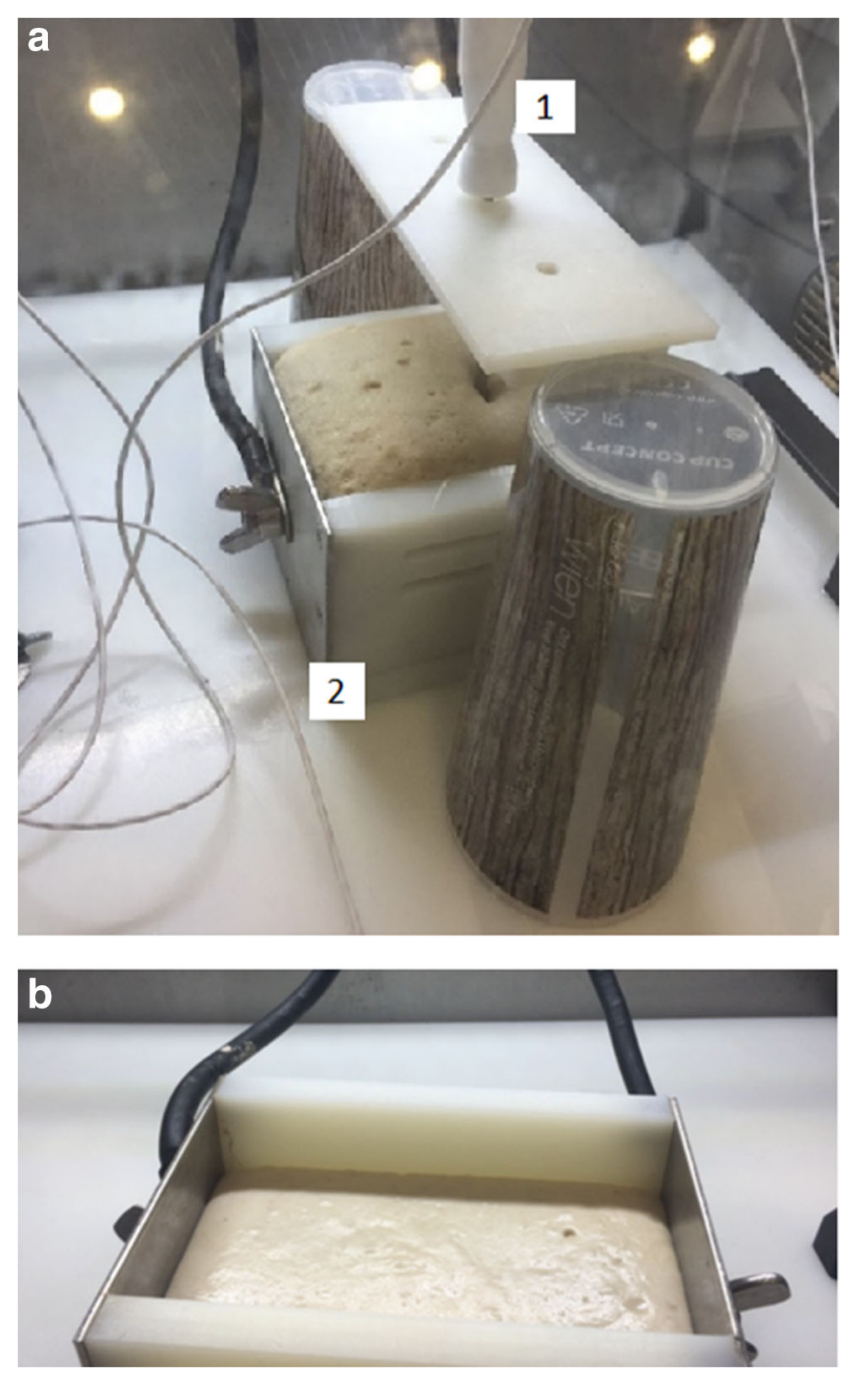

Fig. 1 a Experimental setup of ohmic baking with (1) temperature sensor (2) treatment chamber

Co., Godalming, UK) equipped with a $5 \mathrm{~kg}$ load cell and a SMS $36 \mathrm{~mm}$ diameter compression probe $(\mathrm{P} / 36 \mathrm{R})$ was used. Three $30 \mathrm{~mm}$ slices were cut from the center of each bread loaf and subjected to a uniaxial compression test of 50\% strain at $0.5 \mathrm{~mm} / \mathrm{s}$ speed followed by a relaxation time of $120 \mathrm{~s}$. Preand post-test speeds were $1 \mathrm{~mm} / \mathrm{s}$ and $10 \mathrm{~mm} / \mathrm{s}$, respectively. The crumb firmness represented the maximum force in $\mathrm{N}$ required to deform each cube. The relative elasticity in percent was calculated by dividing the residual force at the end of the relaxation time by the maximum force multiplied by 100 . For each loaf, triplicate measurements were carried out, obtaining 6 values for each tested condition.

Crumb and crust color were measured using a Digi-Eye ${ }^{\circledR}$ system (Verivide, Leicester, UK) integrated with a digital camera D-90 Nikon (Tokyo, Japan). Values of $\mathrm{L}^{*}((0=$ black, $100=$ white $), a *(+$ value $=$ red, - value $=$ green $)$, and $b *(+$ value $=$ yellow, - value $=$ blue $)$ were measured according to the CIELAb system definition. 
Crumb porosity was measured by taking an image of two slices by a digital camera D-90 Nikon (Tokyo, Japan) from the Digi-Eye ${ }^{\circledR}$ System (Verivide, Leicester, UK) and analyzing a $2 \times 2 \mathrm{~cm}$ crumb square with an image analyzer software (ImageJ 1.47v, National Institute of Health, Bethesda, USA) as described by Bender et al. (2018). This software uses the contrast between two phases (pores and solid part) to estimate the pores. The average pore size diameter, pore area (percentage of total pore area by total bread area), and pore count (number of pores) were determined by the software.

\section{Rheological properties of GF breads}

In order to determine the extent of starch modification during $\mathrm{OH}$, pasting properties of all breads were determined as a rough estimation for starch gelatinization. Bread slices used for quality determination were freeze-dried (Freezone 6-Liter Bechntop Freeze Dry System, Labconco, Kansas City, USA) and ground with a mixer (NB 101B, NutriBullet, Los Angeles, USA) for $20 \mathrm{~s}$. Pasting properties of the bread flours were evaluated according to the ICC standard method No. 162 (1996) using a rapid viscoanalyzer (RVA) 4500 (Perten Instruments $\mathrm{AB}$, Hägersten, Sweden). The samples were prepared by dispersing $3.5 \mathrm{~g}$ of flour $(14 \%(\mathrm{w} / \mathrm{w}))$ in $25 \mathrm{ml}$ of distilled water. Determinations were replicated at least three times and the results were shown as mean values.

\section{Starch digestibility}

In vitro starch digestibility was determined according to Englyst et al. (2006) with some modifications. Bread samples were freeze-dried (Freezone 6-Liter Bechntop Freeze Dry System, Labconco, Kansas City, USA) $24 \mathrm{~h}$ after production and ground with a mixer (NB 101B, NutriBullet, Los Angeles, USA) for $20 \mathrm{~s}$. Around $0.3 \mathrm{~g}$ of sample was accurately weighed into Erlenmeyer flasks with 5 glass beads and mixed with $0.25 \mathrm{M}$ sodium acetate buffer $(\mathrm{pH} 5.2)$ for $30 \mathrm{~min}$. Afterwards, $2.5 \mathrm{~mL}$ of an enzymatic mixture containing pancreatin from porcine pancreas (Sigma-Aldrich, St. Louis, USA) and amyloglucosidase $(3300 \mathrm{U} / \mathrm{mL}$; Megazyme International Ireland Ltd., Wicklow, Ireland) as prepared by Englyst et al. (2006) was added and further incubated in a shaking water bath (shaking speed 180 strokes $/ \mathrm{min}$ ) at $37{ }^{\circ} \mathrm{C}$ for $120 \mathrm{~min}$. Aliquots of $0.2 \mathrm{~mL}$ were taken before the addition of the enzymatic mixture and after 20 and $120 \mathrm{~min}$ of incubation with the enzymatic mixture. Aliquots were immediately mixed with $2 \mathrm{~mL}$ of absolute ethanol to stop the enzymatic reaction. The solution was then centrifuged at $500 \times \mathrm{g}$ at $20{ }^{\circ} \mathrm{C}$ for $5 \mathrm{~min}$ and the supernatant was collected. The amount of released glucose was quantified using a glucose oxidase kit following the supplier's instructions (D-Glucose Assay kit; Megazyme International Ireland Ltd., Wicklow, Ireland). Additionally, total starch was measured according to the standard method of AACC No. 76-13.01 (AACC 2000) (Megazyme International Ireland Ltd., Wicklow, Ireland). The content of rapidly digestible starch (RDS), slowly digestible starch (SDS) and resistant starch (RS) were calculated according to Eqs. 1, 2, and 3 and values were expressed as $\mathrm{g} / 100 \mathrm{~g}$ bread flour:

$$
\begin{aligned}
& R D S=(G 20-F G) \times 0.9 \\
& S D S=(G 120-G 20) \times 0.9 \\
& R D S=T S-(S D S+R D S)
\end{aligned}
$$

where FG represented the free glucose measured before the addition of the enzymatic mixture; G20 and G120 was the glucose content after 20 and 120 min of digestion, respectively; TS represented the total starch content of the sample; 0.9 was the conversion factor of glucose to starch.

\section{Data Analysis}

Statistical analyses were performed using STATGRAPHICS Centurion XVII, version 17.1.04 (Statpoint Technologies, Inc., Warrenton, Virginia, USA) and parameters were expressed as mean \pm standard deviation. One-way ANOVA (analysis of variance with $\alpha=0.05$ ) and Fisher's least significance tests were used to express statistical significant differences between treatments. Significant differences were indicated by different letters when $p$ value was lower or equal to 0.05 .

\section{Results and Discussion}

\section{Identification of a suitable processing window for Ohmic baking of GF bread}

The effect of power input ( 0.25 to $7.5 \mathrm{~kW}$ ) on baking performance and behavior of the batter was evaluated and compared within tested conditions. It was observed that a high initial power input was necessary to fixate the structure of the bread. However, exceeding a certain power level $(>6 \mathrm{~kW})$, heating rate and temperature resulted in the formation of crevices in the batter in a layer close to the electrode. This was more visible in batters heated with a higher power, as these dried faster. In cases where the power was higher than $6 \mathrm{~kW}$, arcing occurred leading to crumb burning. Therefore, heating rate in the first baking step had to be limited and the additional energy necessary to finalize the baking had to be split in two additional steps as part of the heating profile. A subsequent reduction of the power level in step two and again in step three was found to be optimal in order to maximize the bread expansion while decreasing the burning risk. High initial power levels in step one $(5-7.5 \mathrm{~kW})$ allowed a high volume 
expansion, although this high-energy input had to be controlled carefully. A period of $15 \mathrm{~s}$ was identified to deliver best results at this power level as the GF batter expanded completely within this period, but the "bread" was not fully stabilized yet, rather resembling a soft, still moist "foam." Thus, additional energy was applied but at lower power in order to continue the baking process. Decreasing the power to a too large extent (e.g., from $7.5-5 \mathrm{~kW}$ directly down to 0.3 $\mathrm{kW}$ ) was found to cause a partial collapse of the well expanded bread. An abrupt decrease of power also increased the risk of arcing and bread burning. As a result of the partial collapse of the bread occurring when a certain energy input is not maintained, a slight horizontal bread shrinking was observed and air spaces occurred between the bread and the electrodes (Fig. 2f II). It is hypothesized that this may lead to an increased electrical resistance between the high-voltage electrode and batter and to channeling due to a non-uniform surface contact, resulting in arcing and crust burning.
Hence, step two in the heating profile was designed as an intermediate heating step and a power level of $1 \mathrm{~kW}$ was found to deliver the appropriate amount of energy in order to avoid the collapse of the bread and overheating at the same time. A holding time of $10 \mathrm{~s}$ led to the further development of the bread structure allowing a further reduction of the power input to $0.3 \mathrm{~kW}$ during a third baking step. With this power profile, an adequate starting point for further and more detailed research was established.

\section{Impact of heating rate and holding time during $\mathrm{OH}$ on gluten-free bread properties}

Based on the identified processing window for the ohmic baking of gluten-free bread, a more detailed investigation of the role of power input, heating rate, and holding time was performed. As a first approach, the power applied in the first step was varied in a broader range between 2 and $8 \mathrm{~kW}$ with a
Fig. 2 Effect of the heating profile on surface and pore structure of gluten-free buckwheat breads baked with ohmic heating at different power input levels applied during the first heating step. a $2 \mathrm{~kW}$; $4 \mathrm{~kW}$; c $5 \mathrm{~kW}$; d $6 \mathrm{~kW}$; e $8 \mathrm{~kW}$; I. a-e three heating steps; II. a-e step one and three only; $\mathbf{f}$ I: conventional oven baking; $\mathbf{f}$ II: collapse and burning of the bread at unfavorable $\mathrm{OH}$ conditions
I.

a

b
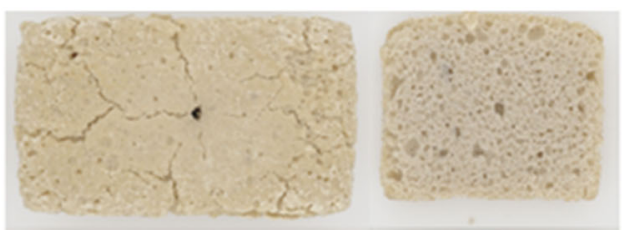

C

d

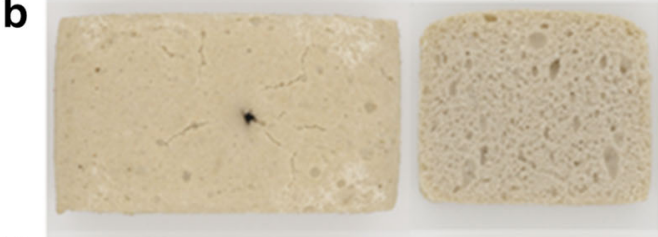

e

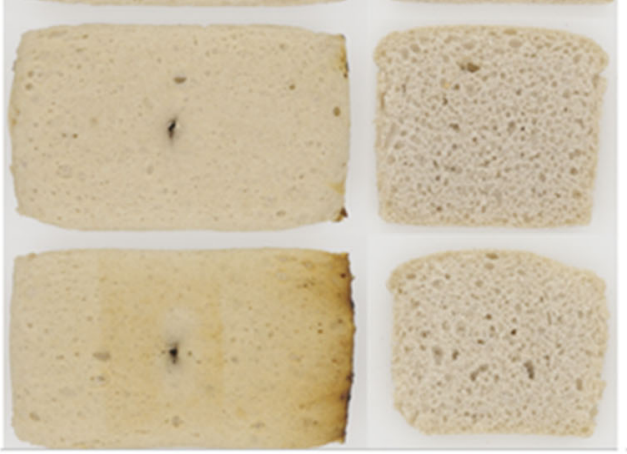

f

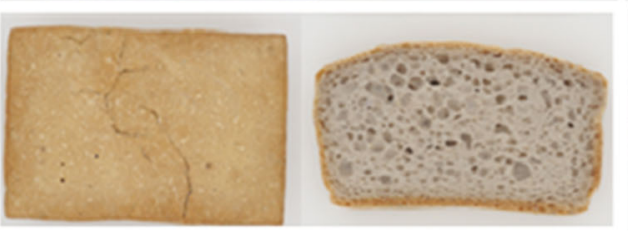

II.

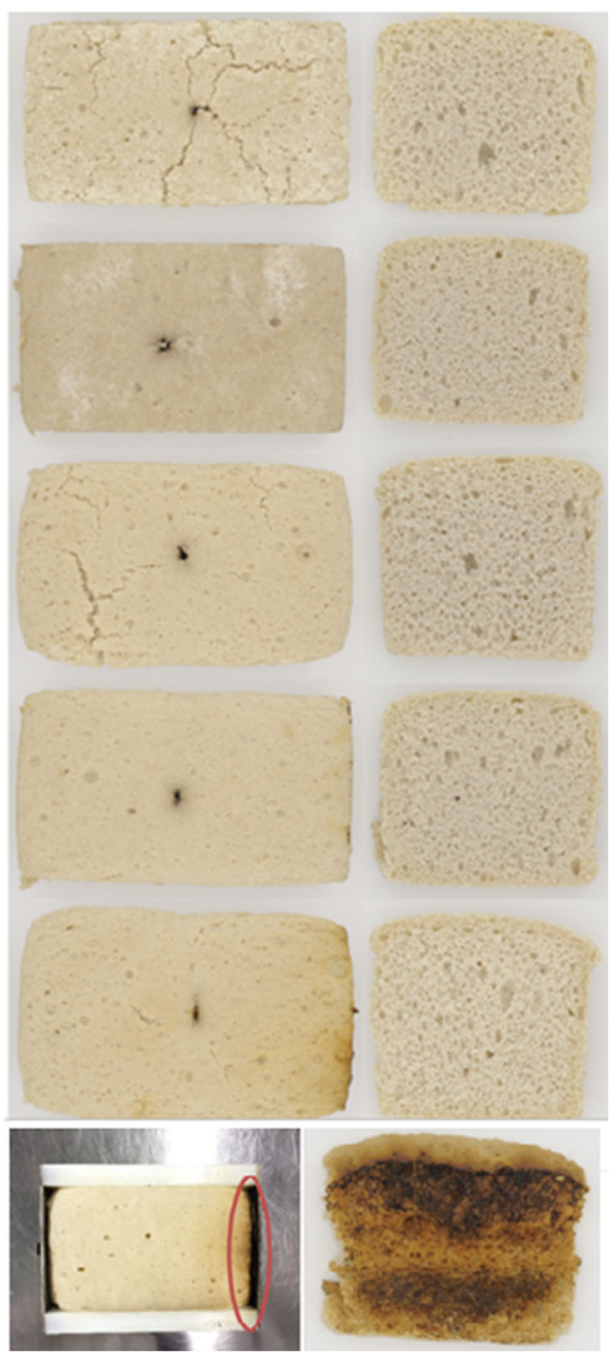


holding time of $15 \mathrm{~s}$, whereas the subsequent heating steps were kept at constant conditions of $1 \mathrm{~kW}$ for $10 \mathrm{~s}$ followed by $0.3 \mathrm{~kW}$ for $5 \mathrm{~min}$. In addition, a second scenario was investigated for which the second heating step was omitted and the first heating step ( 2 to $8 \mathrm{~kW}$ for $15 \mathrm{~s}$ ) was followed by abruptly descending the power directly down to the third heating step $(0.3 \mathrm{~kW}$ for $5 \mathrm{~min})$. The structural and functional bread properties were evaluated in detail for both cases.

The temperature profile of gluten-free batters heated with different initial power levels can be taken from Fig. 3. Almost all bread batters reached $100{ }^{\circ} \mathrm{C}$, except for the breads heated with an initial power of $8 \mathrm{~kW}$. In this case, the heating process had to be stopped after $15 \mathrm{~s}$ at the end of the first heating step as the bread started to burn. For comparative means, these breads were still analyzed although a power level of $8 \mathrm{~kW}$ was then discarded for further optimization. For similar reasons, the final holding time of breads heated with $6 \mathrm{~kW}$ was reduced from 5 to $3 \mathrm{~min}$. Bread burning always occurred next to the high voltage electrode, as seen in Fig. $2 \mathrm{f} \mathrm{II.} \mathrm{In} \mathrm{general,}$ higher power inputs significantly increased the heating rate in $\mathrm{OH}$ treatments, which was slightly enhanced when the second step was present. $\mathrm{OH}$ heating profiles that led to the best bread quality reached a reference core temperature of $90^{\circ} \mathrm{C}$ in $37 \mathrm{~s}$, whereas conventionally baked breads required $20.6 \mathrm{~min}$ to reach the same temperature.

Effect on physical properties of gluten-free bread Table 1 summarizes the influence of different initial power inputs (2 to $8 \mathrm{~kW}$ for $15 \mathrm{~s}$ ) and the effect of the presence of a second heating step $(1 \mathrm{~kW}$ for $10 \mathrm{~s})$ on gluten-free bread properties. Overall, bread properties were positively affected by $\mathrm{OH}$, compared with conventionally baked breads. During $\mathrm{OH}$, the initial heating step was the crucial factor for determining the final GF bread properties, rather than the subsequent ongoing heating steps (second and third step). With increasing initial power, breads displayed a slight increase in specific volume. Masure et al. (2018) studied the crumb structure formation of GF breads baked with an electrical resistance oven. They observed that the final loaf volume was defined by the moment at which the crumb structure was fixed before releasing $\mathrm{CO}_{2}$ from the pores. This suggests that all bread in this investigation reached a fixed structure rapidly enough before
Fig. 3 Core temperature evolution of batter during ohmic heating a with second heating step; b without a second heating step. I, different power levels as indicated, holding time $15 \mathrm{~s}$; II, $1 \mathrm{~kW}$ for $10 \mathrm{~s}$; III, $0.3 \mathrm{~kW}$ for 5 $\min$
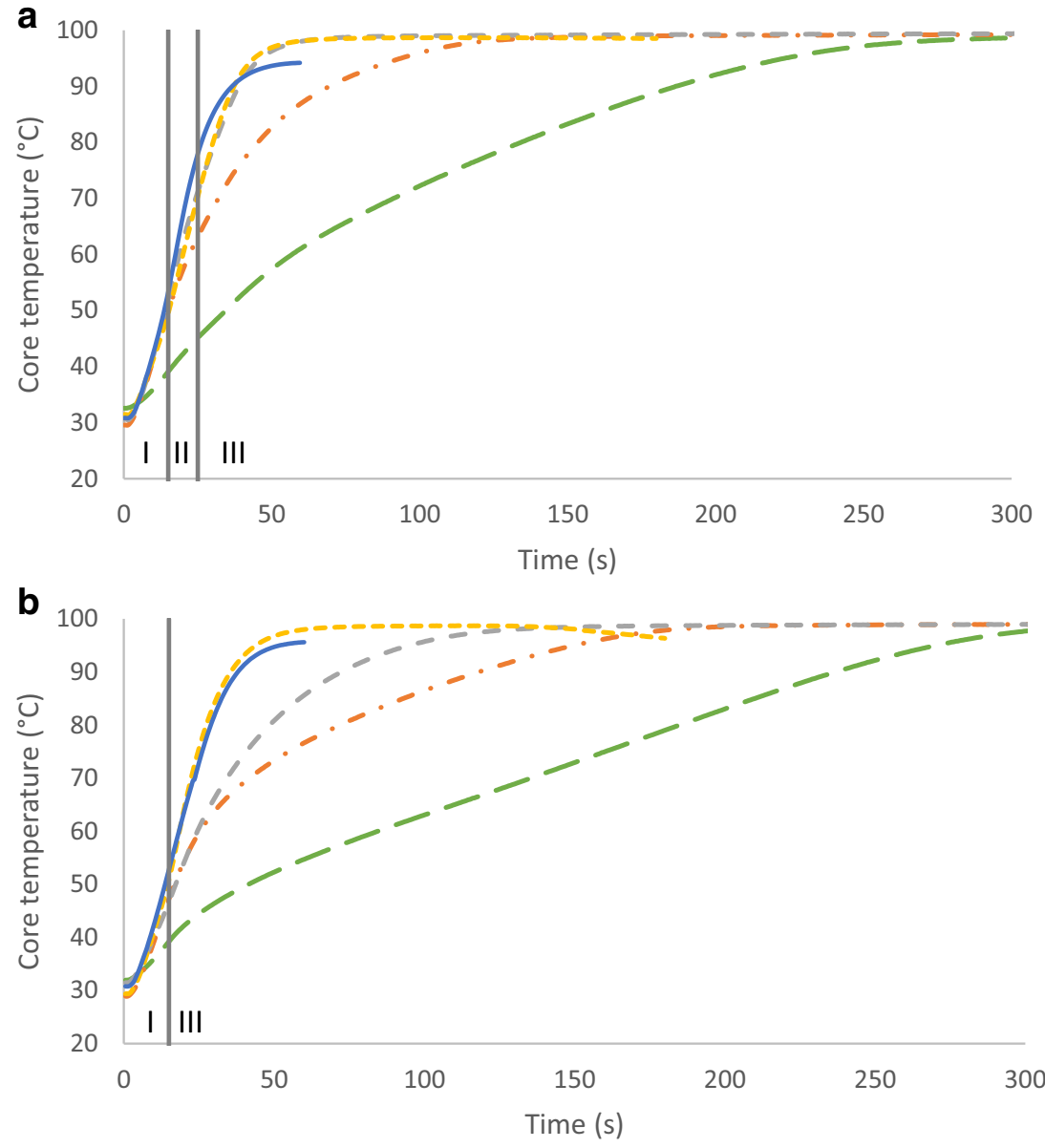

Step I: $-2 \mathrm{~kW}-.-4 \mathrm{~kW}---5 \mathrm{~kW}---0.6 \mathrm{~kW}-8 \mathrm{~kW}$ 


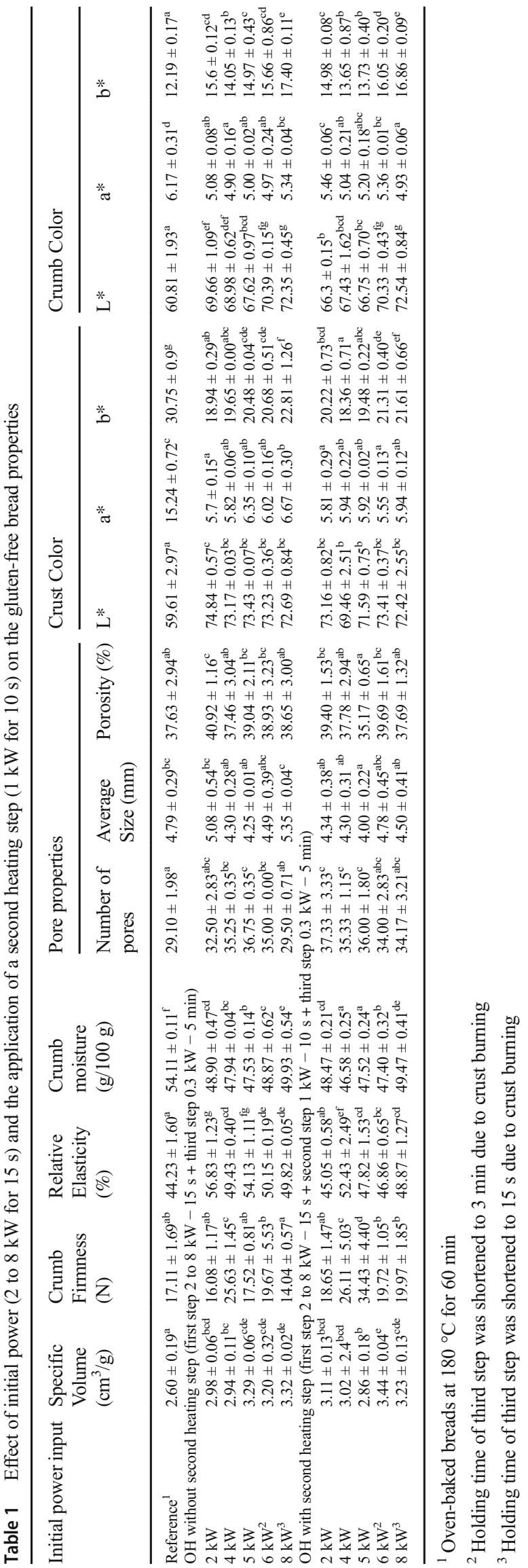

$\mathrm{CO}_{2}$ release took place, leading to significantly higher bread volumes than conventionally baked breads.

Crumb firmness, relative elasticity and crumb moisture were also affected by the different initial power inputs. Most of the $\mathrm{OH}$ breads displayed a similar crumb firmness, but significantly higher relative elasticity than conventionally baked breads, which could eventually be related to the differences in crumb moisture distribution. Derde et al. (2014) and He and Hoseney (1991) described that during heating, different water distribution mechanisms occurred, leading to major changes in crumb moisture. In conventional heating, water vapor that is formed in the warmer outer regions of the bread condenses in the center, which is slightly cooler than its surroundings. In case of $\mathrm{OH}$ breads, water vapor is generated in the center of the bread and condenses in the colder outer surface of the batter from where it can evaporate more easily. This explains why $\mathrm{OH}$ breads had lower crumb moistures, compared with the reference breads. These differences in crumb moisture might also have influenced crumb properties.

Pore properties and crust and crumb color of the breads remained mostly unaffected by the different $\mathrm{OH}$ treatments, but compared with the control breads, $\mathrm{OH}$ breads were much lighter $\left(\mathrm{L}^{*}\right)$ and had a lower redness $\left(\mathrm{a}^{*}\right)$ and yellowness $\left(\mathrm{b}^{*}\right)$ than the latter, except for the crumb color, which showed an opposite trend. Lund and Ray (2017) reported that due to the short time high temperature heating and evenly distributed heat, Maillard reactions can be controlled or even minimized during $\mathrm{OH}$, which would explain the differences in color. Also, number of pores and porosity were significantly higher in most $\mathrm{OH}$ breads, whereas average pore size remained the same. Probably the batter properties, especially the egg white powder in the formulation, contributed to a higher stabilization of the gas cells. This may have reduced the risk of coalescence and/or collapse during the different $\mathrm{OH}$ treatments (Kiosseoglou and Paraskevopoulou 2014). Images of OH breads and the conventionally baked bread can be taken from Fig. 2, which shows that $\mathrm{OH}$ breads seemed to have a finer and more evenly distributed pore structure. $\mathrm{OH}$ breads heated at a low initial power, especially at 2 and $4 \mathrm{~kW}$, exhibited a fractured crust surface that emerged after cooling. Crust defects like these are common in breads baked at low temperatures (Reineke 2009) and could be related to the lower heating rates seen in breads heated with 2 and $4 \mathrm{~kW}$ (see Fig. 3). These breads also exhibited white spots in the crust, which might be associated with non-gelatinized starch. Derde et al. (2014) determined the rise in temperature of breads during $\mathrm{OH}$ treatment at different locations. They detected that the temperature of the dough nearest to the crust surface was significantly lower than the temperatures measured at the center of the bread loaf. Therefore, the lower heating rate of 2 and $4 \mathrm{~kW}$ and the non-uniform temperature distribution with lower temperatures toward the crust surface might explain the irregular 
starch gelatinization. However, additional investigations are required in order to determine the temperature distribution during the course of baking.

From these trials, lowest and highest power levels of $2 \mathrm{~kW}$ and $6 \mathrm{~kW}$ were selected as appropriate limits for the $\mathrm{OH}$ treatment. In further experiments, the holding time during the third heating step was varied from 0 to $30 \mathrm{~min}$ and adjusted accordingly. The second heating step was included during the heating profile, as this was shown to positively influence GF bread properties.

Table 2 summarizes the effect of different holding times on the functional properties of breads heated at 2 and $6 \mathrm{~kW}$ initial power. In general, holding time did not influence most of the bread properties significantly and no clear relationship between this variable and the relative elasticity or pore properties could be established. Only breads heated with $6 \mathrm{~kW}$ showed an increase in pore size when excluding the third heating step but a reason for this behavior is still unclear.

Effect on RVA pasting properties Pasting properties of $\mathrm{OH}$ and conventionally baked breads with different initial power levels can be taken from Fig. 4A and B. Overall, these properties were significantly enhanced in $\mathrm{OH}$ breads by increasing initial power and all $\mathrm{OH}$ breads showed higher values compared with the control bread. Many factors might be responsible for these phenomena, such as the degree of starch gelatinization which could have been different depending on the heating profile. Also, a different extent of starch retrogradation needs to be taken into account, since the measurement was performed $18 \mathrm{~h}$ after baking. Starch swelling and water absorption capacity, different crystallization after baking but also interference with other bread ingredients are further factors to be considered (Lund 1984). Therefore, RVA determination provided no clear answer to one of these phenomena, but it allowed to follow to a certain degree the baking effect on the crumb structure.

The lower pasting profile in the control breads suggested that starch in this bread might have been more gelatinized than in the $\mathrm{OH}$ breads, but starch crystallization effects upon cooling or storage could also have contributed to this behavior. This might be related to the different heating mechanisms involved in both baking methods, as well as their duration. In general, $\mathrm{OH}$ is able to heat solid food at the same rate as liquids, as heat is generated volumetrically based on the electrical conductivity of the different fractions. In case of conventional heating, the heating closely depends on the ability of the liquid phase to transfer the heat to the solid phase (Fryer et al. 1993). Conventional baking exposes starch to high temperatures for a longer period, which further influences the structural properties of starch.

Pasting viscosities of breads were increased when applying higher initial power. The faster heating rate and the shorter time to reach $100{ }^{\circ} \mathrm{C}$ during $\mathrm{OH}$, might have led to improper starch gelatinization during $\mathrm{OH}$ treatment, which might explain the RVA crumb viscosity data. Another reason could be an electroporation effect of $\mathrm{OH}$ on starch as suggested by An and King (2007). These authors reported similar results since they observed that higher $\mathrm{OH}$ treatment intensities produced rice flour with faster swelling properties, compared with low intensity $\mathrm{OH}$ treatments. Authors related this finding to a more permeable starch structure that could retain more water. An altered crystallinity might have also played a role, because interestingly, applying a second $\mathrm{OH}$ heating step (thus a higher energy input) reduced the pasting properties.

Regarding the $\mathrm{OH}$ breads that underwent a longer holding time at $0.3 \mathrm{~kW}$ (step 3), their pasting properties were significantly reduced with increasing holding time (see Fig $3 \mathrm{C}$ and D). A similar outcome has been observed by An and King

Table 2 Effect of holding time of the third heating step of selected $\mathrm{OH}$ treatments on gluten-free bread properties ${ }^{1}$

\begin{tabular}{|c|c|c|c|c|c|c|c|}
\hline \multirow{2}{*}{$\begin{array}{l}\text { Initial power } \\
(\mathrm{kW})\end{array}$} & \multirow{2}{*}{$\begin{array}{l}\text { Holding time } \\
\text { (min) }\end{array}$} & \multirow{2}{*}{$\begin{array}{l}\text { Specific volume } \\
\left(\mathrm{cm}^{3} / \mathrm{g}\right)\end{array}$} & \multirow[t]{2}{*}{ Crumb firmness $(\mathrm{N})$} & \multirow[t]{2}{*}{ Relative Elasticity (\%) } & \multicolumn{3}{|l|}{ Pore properties } \\
\hline & & & & & Count & Average size (mm) & Pore area $(\%)$ \\
\hline \multirow[t]{4}{*}{2} & $5^{2}$ & $3.11 \pm 0.13^{\mathrm{ab}}$ & $18.65 \pm 1.47^{\mathrm{b}}$ & $45.05 \pm 0.58^{\mathrm{a}}$ & $37.33 \pm 3.33^{\mathrm{cd}}$ & $4.34 \pm 0.38^{\mathrm{a}}$ & $39.40 \pm 1.53^{\mathrm{bc}}$ \\
\hline & 7.5 & $3.02 \pm 0.03^{\mathrm{a}}$ & $19.38 \pm 1.16^{\mathrm{b}}$ & $48.26 \pm 0.43^{\mathrm{cd}}$ & $26.50 \pm 3.27^{\mathrm{a}}$ & $5.75 \pm 0.77^{\mathrm{c}}$ & $39.30 \pm 2.87^{\mathrm{bc}}$ \\
\hline & 10 & $2.95 \pm 0.02^{\mathrm{a}}$ & $24.00 \pm 0.29^{\mathrm{c}}$ & $46.54 \pm 0.01^{\mathrm{b}}$ & $30.75 \pm 2.93^{b}$ & $5.08 \pm 0.28^{\mathrm{bc}}$ & $40.13 \pm 1.64^{\mathrm{c}}$ \\
\hline & 30 & $2.94 \pm 0.10^{\mathrm{a}}$ & $31.41 \pm 2.08^{\mathrm{d}}$ & $44.49 \pm 0.41^{\mathrm{a}}$ & $39.50 \pm 1.97^{\mathrm{d}}$ & $4.04 \pm 0.28^{\mathrm{a}}$ & $39.12 \pm 0.80^{\mathrm{bc}}$ \\
\hline \multirow[t]{4}{*}{6} & 0 & $3.26 \pm 0.02^{\mathrm{bc}}$ & $14.18 \pm 0.02^{\mathrm{a}}$ & $49.79 \pm 0.19^{\mathrm{e}}$ & $23.00 \pm 1.41^{\mathrm{a}}$ & $6.66 \pm 0.47^{\mathrm{d}}$ & $37.71 \pm 0.64^{\mathrm{ab}}$ \\
\hline & 1 & $3.25 \pm 0.07^{\mathrm{bc}}$ & $19.47 \pm 1.85^{\mathrm{b}}$ & $47.79 \pm 1.4^{\mathrm{bcd}}$ & $30.75 \pm 0.35^{\mathrm{b}}$ & $4.93 \pm 0.04^{\mathrm{bc}}$ & $36.81 \pm 0.55^{\mathrm{a}}$ \\
\hline & 2 & $3.30 \pm 0.13^{\mathrm{c}}$ & $16.62 \pm 1.66^{\mathrm{ab}}$ & $48.65 \pm 0.35^{\mathrm{de}}$ & $32.75 \pm 3.89^{\mathrm{b}}$ & $4.94 \pm 0.67^{\mathrm{bc}}$ & $40.15 \pm 0.34^{\mathrm{c}}$ \\
\hline & $3^{2}$ & $3.44 \pm 0.04^{\mathrm{c}}$ & $19.72 \pm 1.05^{\mathrm{b}}$ & $46.86 \pm 0.65^{\mathrm{bc}}$ & $34.00 \pm 2.83^{b c}$ & $4.78 \pm 0.45^{\mathrm{b}}$ & $39.69 \pm 1.61^{b c}$ \\
\hline
\end{tabular}

RDS, rapidly digestible starch; SDS, slowly digestible starch; RS, resistant starch

${ }^{1} \mathrm{OH}$ process: first step 2 or $6 \mathrm{~kW}-15 \mathrm{~s}+$ second step $1 \mathrm{~kW}-10 \mathrm{~s}+$ third step $0.3 \mathrm{~kW}$ - variable holding time

${ }^{2}$ Starting conditions from which the optimization was performed 

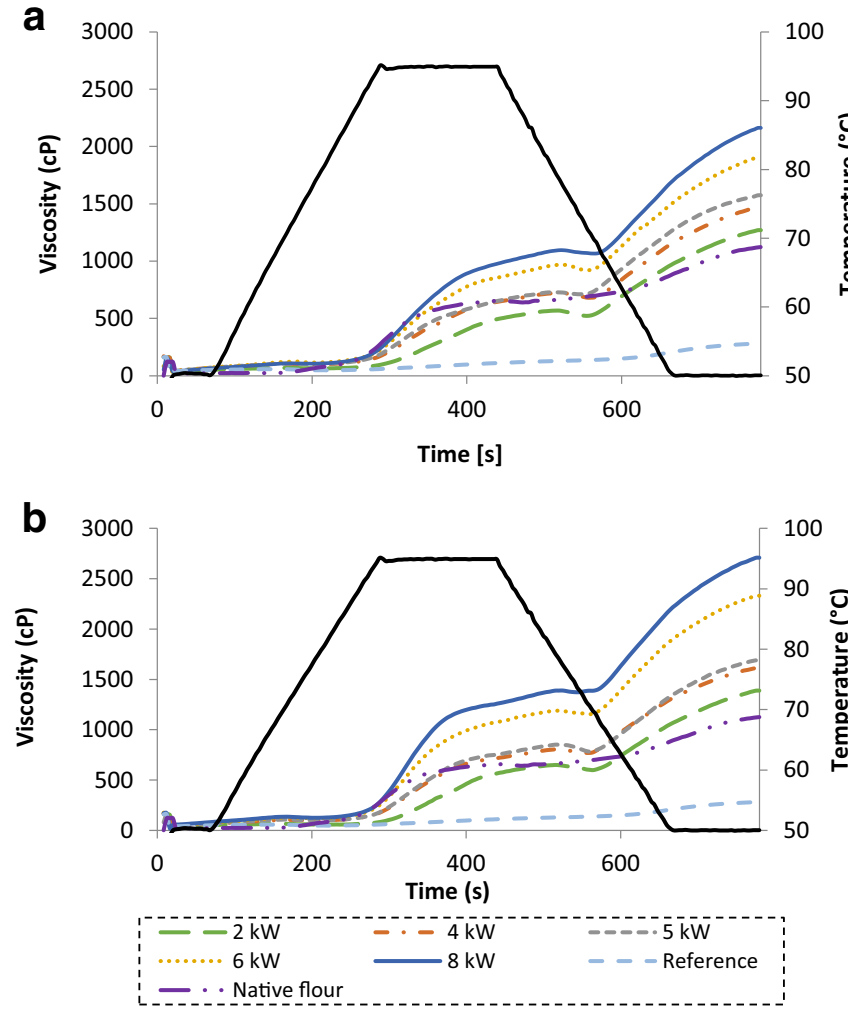

Fig. 4 Pasting properties of native buckwheat flour and flour recovered from $\mathrm{OH}$ breads heated with different initial power levels during the first heating step a with a second heating step of $1 \mathrm{~kW}$ for $15 \mathrm{~s}$ followed by $0.3 \mathrm{~kW}$ for $5 \mathrm{~min}$; b without a second heating step but holding at $0.3 \mathrm{~kW}$

(2007). These investigators assessed the degree of gelatinization of rice flour by differential scanning calorimetry (DSC) and observed that a treatment at higher electric field strength but shorter treatment time $(70 \mathrm{~V} / \mathrm{cm}$ for $76 \mathrm{~s})$ was not able to fully pre-gelatinize the sample. In contrast, a treatment at lower field strength and longer treatment time $(20 \mathrm{~V} / \mathrm{cm}$ for 20.2 $\min$ ) increased the extent of gelatinization. Due to the lower heating rate, starch was allowed to swell and solubilize properly, undergoing a higher gelatinization and decreasing its
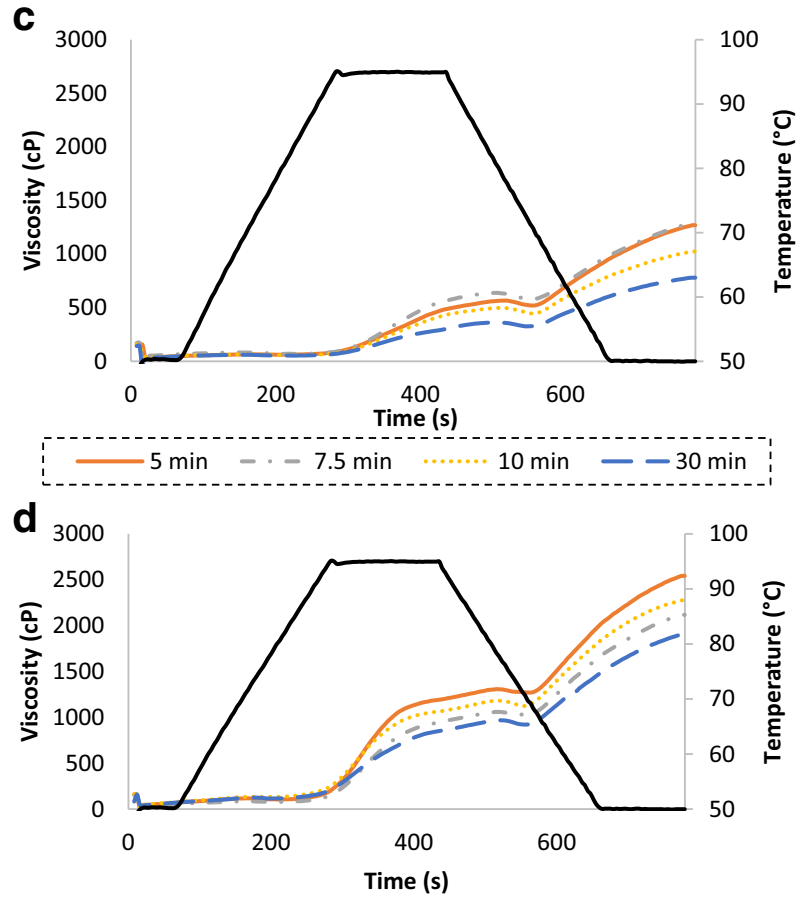

$0 \mathrm{~min}-1 \mathrm{~min} \cdots \cdots 2 \mathrm{~min}--3 \mathrm{~min}$

for $5 \mathrm{~min}$; compared with conventionally baked bread (reference). Pasting properties of $\mathrm{OH}$ breads baked at different holding times for the third baking step at $0.3 \mathrm{~kW}$ c with initial power of $2 \mathrm{~kW}$; d with initial power of $6 \mathrm{~kW}$; for both, a second heating step was applied

thermal enthalpy in the differential scanning calorimetry (DSC).

\section{Effect of prolonged $\mathrm{OH}$ treatment time on starch digestibility}

This study showed that $\mathrm{OH}$ can significantly improve GF bread properties, compared with conventional baking. Nevertheless, a full understanding of the chemical and
Fig. 5 Effect of selected $\mathrm{OH}$ treatments and conventional baking of GF bread on the digestibility of starch. RDS, rapidly digestible starch; SDS, slowly digestible starch; RS, resistant starch; reference, conventional baking

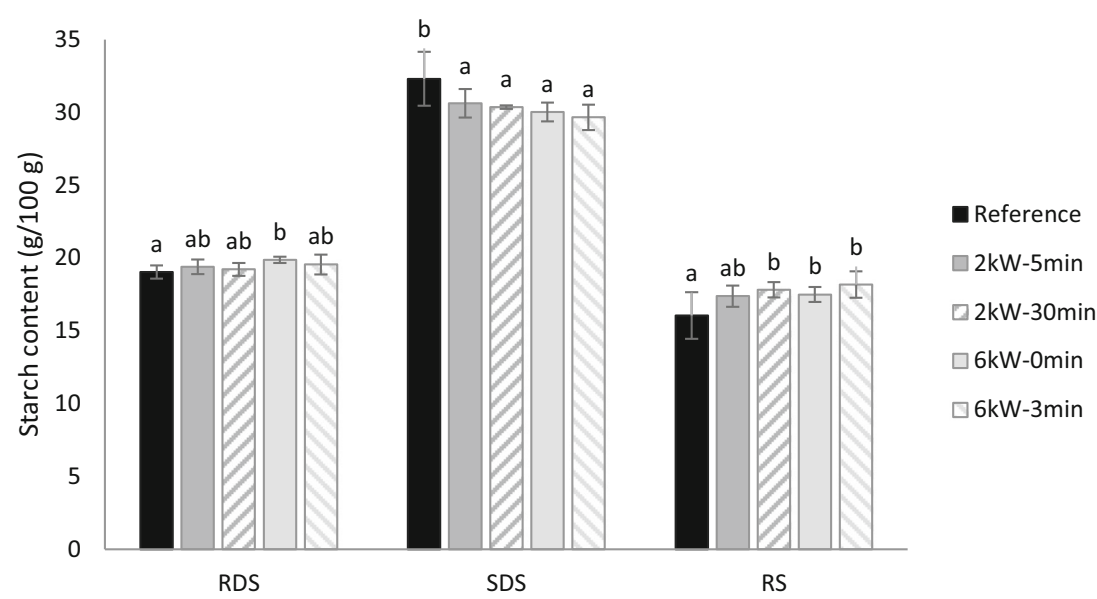


structural changes that occur in the bread during $\mathrm{OH}$ is necessary. In conventional baking, the batter reaches its maximum temperature at around $100{ }^{\circ} \mathrm{C}$, allowing starch to gelatinize and paste, proteins to denature and water to evaporate at a slow rate. Since in $\mathrm{OH}$ treatments this temperature is reached and held for such a short time, it remains questionable whether starch can be properly gelatinized during this period. This could significantly affect its digestibility. Especially in $\mathrm{OH}$ breads treated with high initial power (e.g., 6 and $8 \mathrm{~kW}$ ), treatment time has to be kept short due to the rapid water evaporation of the batter, which might lead to improper starch swelling. On the other hand, breads heated at a slower rate would only be exposed to high temperatures for a very short time either, which might also affect its digestibility.

Indirect information about the extent of starch disruption was gained by in vitro digestibility methods, which is shown in Fig. 5. Surprisingly, neither holding time nor initial power, thus neither long nor short heat exposure, significantly influenced starch digestibility of the $\mathrm{OH}$ breads. However, compared with the control bread, the $\mathrm{OH}$ breads showed an increased RS content and a slight but significantly lower SDS content. A higher amount of amylose re-organization, amylopectin retrogradation or starch granule recrystallization of the breads was related to higher amylose leaching due to modification of starch structure (An and King 2007). Nevertheless, more studies would be necessary to fully understand the extent of structural modification that starch is subjected to during $\mathrm{OH}$ and to differentiate between thermal and electric field effects that may occur. In particular, application of DSC might deliver valuable insight on the phase transition that starch undergoes during thermal treatment and its interaction with other constituents within the food matrix (Yu and Christie 2001; Eliasson 1994; Lii and Lee 1993).

\section{Conclusion}

This study demonstrated that $\mathrm{OH}$ was a suitable and promising technology for the production of GF crustless bread. It showed the need to implement a heating profile with variable power in different heating steps in order to achieve an optimized product quality (i.e. specific volume, elasticity, and porosity).

Compared with conventional baking, $\mathrm{OH}$ has shown many advantages in terms of improved bread quality and reduced baking time. Starch digestibility of the breads baked with $\mathrm{OH}$ was slightly reduced, compared with conventional baking, this resulted in breads with higher RS content, which has been associated to several health-related benefits (Birt et al. 2013). Furthermore, $\mathrm{OH}$ might even reduce processing costs, as baking is known to consume most of the energy (around 40\%) during bread making (Kannan and Boie 2003). It can already be inferred by the water evaporation during both baking methods, that the energy consumption during conventional baking (water loss, 13.97\%) was at least thrice as high during baking than in case of $\mathrm{OH}$ (water loss, 1.92-4.31\%). Although energy expenditure of $\mathrm{OH}$ in industrial scale cannot be transferred directly from the pilot scale equipment and remains unknown, it might provide economical advantage over conventional baking methods. Moreover, due to the use of high frequencies (kHz range in this study), the electrochemical reactions at the electrode interface may be reduced, minimizing corrosion and leakage of metals to the heating medium, as reported by Samaranayake et al. (2005) and Pataro et al. (2014)

Overall, this process is still in need of optimization and further fundamental research should be carried out in order to understand the behavior of the batter and its components (e.g., starch, protein) during $\mathrm{OH}$ and to further optimize the process variables for a tailored and targeted processing. By testing model systems with isolated polymers such as starch, changes induced by the $\mathrm{OH}$ might be better understood and could provide useful information to determine the effect of $\mathrm{OH}$ on the bread quality.

Funding Information Open access funding provided by University of Natural Resources and Life Sciences Vienna (BOKU). This work was partly supported by the Austrian Research Promotion Agency (FFG Project No. 859077) and was created within a research project of the Austrian Competence Centre for Feed and Food Quality, Safety and Innovation (FFoQSI). The COMET-K1 competence centre FFoQSI is funded by the Austrian ministries BMVIT, BMDW and the Austrian provinces Niederoesterreich, Upper Austria and Vienna within the scope of COMET - Competence Centers for Excellent Technologies. The programme COMET is handled by the Austrian Research Promotion Agency FFG.

\section{Compliance with Ethical Standards}

Conflict of Interest The authors declare that they have no conflict of interest.

Open Access This article is distributed under the terms of the Creative Commons Attribution 4.0 International License (http:// creativecommons.org/licenses/by/4.0/), which permits unrestricted use, distribution, and reproduction in any medium, provided you give appropriate credit to the original author(s) and the source, provide a link to the Creative Commons license, and indicate if changes were made.

\section{References}

AACC. (2000). Approved methods of the American Association of Cereal Chemists (10th ed.). St. Paul: AACC Intl..

An, H. J., \& King, J. M. (2007). Thermal Characteristics of ohmically heated rice starch and rice flours. Journal of Food Science, 72(1), C084-C088. https://doi.org/10.1111/j.1750-3841.2006.00239.x.

Bender, D., Regner, M., D’Amico, S., Tömösközi, S., Jäger, H., \& Schoenlechner, R. (2018). Effect of differently extracted 
arabinoxylan on gluten-free sourdough-bread properties. Journal of Food Quality, 10.

Birt, D. F., Boylston, T., Hendrich, S., Jane, J.-L., Hollis, J., Li, L., McClelland, J., Moore, S., Phillips, G. J., Rowling, M., Schalinske, K., Scott, M. P., \& Whitley, E. M. (2013). Resistant starch: promise for improving human health. Advances in Nutrition, 4(6), 587-601. https://doi.org/10.3945/an.113.004325.

Chhanwal, N., Tank, A., Raghavarao, K. S. M. S., \& Anandharamakrishnan, C. (2012). Computational fluid dynamics (CFD) modeling for bread baking process - a review. Food and Bioprocess Technology, 5(4), 1157-1172. https://doi.org/10.1007/ s11947-012-0804-y.

Derde, L. J., Gomand, S. V., Courtin, C. M., \& Delcour, J. A. (2014). Moisture distribution during conventional or electrical resistance oven baking of bread dough and subsequent storage. Journal of Agriculture and Food Chemistry, 62(27), 6445-6453. https://doi. org $/ 10.1021 / \mathrm{jf5} 01856 \mathrm{~s}$.

Eliasson, A. C. (1994). Interaction between starch and lipids studied by DSC. Thermochimica Acta, 246(2), 343-356. https://doi.org/10. 1016/0040-6031(94)80101-0.

Englyst, K. N., Hudson, G. J., \& Englyst, H. N. (2006). Starch analysis in food. In R. A. Meyers \& R. J. McGorrin (Eds.), Encyclopedia of analytical chemistry. John Wiley \& Sons, Ltd..

Fryer, P. J., de Alwis, A. A. P., Koury, E., Stapley, A. G. F., \& Zhang, L. (1993). Ohmic processing of solid-liquid mixtures: heat generation and convection effects. Journal of Food Engineering, 18(2), 101125. https://doi.org/10.1016/0260-8774(93)90031-E.

Gally, T., Rouaud, O., Jury, V., \& Le-Bail, A. (2016). Bread baking using ohmic heating technology; a comprehensive study based on experiments and modelling. Journal of Food Engineering, 190, 176-184. https://doi.org/10.1016/j.jfoodeng.2016.06.029.

Hayman, D. A., Hoseney, R. C., \& Faubion, J. M. (1998). Effect of pressure (Crust Formation) on bread crumb grain development. Cereal Chemistry, 75(5), 581-584. https://doi.org/10.1094/ CCHEM.1998.75.5.581.

He, H., \& Hoseney, R. C. (1991). Gas retention in bread dough during baking. Cereal Chemistry, 68, 521-525.

ICC (1996). ICC standard method no. 162. Rapid pasting method using the newport rapid visco analyser vienna. ICC.

Icier, F. (2012). Chapter 11 - ohmic heating of fluid foods. In P. J. Cullen, B. K. Tiwari, \& V. P. Valdramidis (Eds.), Novel thermal and nonthermal technologies for fluid foods (pp. 305-367). San Diego: Academic Press.

Jaeger, H., Roth, A., Toepfl, S., Holzhauser, T., Engel, K.-H., Knorr, D., Vogel, R. F., Bandick, N., Kulling, S., Heinz, V., \& Steinberg, P. (2016). Opinion on the use of ohmic heating for the treatment of foods. Trends in Food Science and Technology, 55, 84-97.

Kannan, R., \& Boie, W. (2003). Energy management practices in SMEcase study of a bakery in Germany. Energy Conversion and Management, 44(6), 945-959. https://doi.org/10.1016/S01968904(02)00079-1.

Kiosseoglou, V., \& Paraskevopoulou, A. (2014). Eggs. In W. Zhou, Y. H. Hui, M. A. De Leyn, M. A. Pagani, C. M. Rosell, J. D. Selman, et al. (Eds.), Bakery products science and technology (pp. 243-258). Hoboken: Wiley-Blackwell.

Kumar, P., Ramanathan, M., \& Ranganathan, T. V. (2014). Ohmic heating technology in food processing - a review. International Journal of Food Engineering Research \& Technology, 3, 1236-1241.
Lii, C. Y., \& Lee, B. L. (1993). Heating A-, B-, and C-type starches in aqueous sodium chloride: effects of sodium chloride concentration and moisture content on differential scanning calorimetry thermograms. Cereal Chemistry, 70, 188-192.

Lund, D. (1984). Influence of time, temperature, moisture, ingredients, and processing conditions on starch gelatinization. Critical Reviews in Food Science and Nutrition, 20(4), 249-273. https://doi.org/10. 1080/10408398409527391.

Lund, M. N., \& Ray, C. A. (2017). Control of maillard reactions in foods: strategies and chemical mechanisms. Journal of Agriculture and Food Chemistry, 65(23), 4537-4552. https://doi.org/10.1021/acs. jafc. $7 b 00882$.

Masure, H. G., Wouters, A. G. B., Fierens, E., \& Delcour, J. A. (2018). Electrical resistance oven baking as a tool to study crumb structure formation in gluten-free bread. Food Research International, 116, 925-931. https://doi.org/10.1016/j.foodres.2018.09.029.

Mondal, A., \& Datta, A. K. (2008). Bread baking - a review. Journal of Food Engineering, 86(4), 465-474. https://doi.org/10.1016/j. jfoodeng.2007.11.014.

Pataro, G., Barca, G. M. J., Pereira, R. N., Vicente, A. A., Teixeira, J. A., \& Ferrari, G. (2014). Quantification of metal release from stainless steel electrodes during conventional and pulsed ohmic heating. Innovative Food Science \& Emerging Technologies, 21, 66-73. https://doi.org/10.1016/j.ifset.2013.11.009.

Phimolsiripol, Y., Mukprasirt, A., \& Schoenlechner, R. (2012). Quality improvement of rice-based gluten-free bread using different dietary fibre fractions of rice bran. Journal of Cereal Science, 56(2), 389395. https://doi.org/10.1016/j.jcs.2012.06.001.

Reineke, D. (2009). Fehler bei Brot und Kleingebäck und deren Beseitigung. Bonn: Wissensforum Backwaren e.V.

Sakr, M., \& Liu, S. (2014). A comprehensive review on applications of ohmic heating $(\mathrm{OH})$. Renewable and Sustainable Energy Reviews, 39, 262-269. https://doi.org/10.1016/j.rser.2014.07.061.

Samaranayake, C. P., Sastry, S. K., \& Zhang, H. (2005). Pulsed ohmic heating-a novel technique for minimization of electrochemical reactions during processing. Journal of Food Science, 70(8), e460 e465. https://doi.org/10.1111/j.1365-2621.2005.tb11515.x.

Schoenlechner, R., Mandala, I., Kiskini, A., Kostaropoulos, A., \& Berghofer, E. (2010). Effect of water, albumen and fat on the quality of gluten-free bread containing amaranth. International Journal of Food Science \& Technology, 45(4), 661-669. https://doi.org/10. 1111/j.1365-2621.2009.02154.x.

Varghese, K. S., Pandey, M. C., Radhakrishna, K., \& Bawa, A. S. (2014). Technology, applications and modelling of ohmic heating: a review. [journal article]. Journal of Food Science and Technology, 51(10), 2304-2317. https://doi.org/10.1007/s13197-012-0710-3.

Yu, L., \& Christie G., (2001) Measurement of starch thermal transitions using differential scanning calorimetry. Carbohydrate Polymers 46(2), 179-184.

Publisher's Note Springer Nature remains neutral with regard to jurisdictional claims in published maps and institutional affiliations. 